\title{
Predicting prey capture rates of southern elephant seals from track and dive parameters
}

\author{
Jade Vacquié-Garcia*,1, Christophe Guinet ${ }^{1}$, Anne-Cécile Dragon ${ }^{2}$, \\ Morgane Viviant ${ }^{1}$, Nory El Ksabi ${ }^{1}$, Frédéric Bailleul ${ }^{1}$ \\ ${ }^{1}$ Centre d'Etudes Biologiques de Chizé (CEBC), CNRS UPR 1934, 79360 Villiers-en-bois, France \\ ${ }^{2}$ Collecte Localisation Satellites (CLS Argos), 8-10 rue Hermès, 31520 Ramonville-Saint-Agne, France
}

\begin{abstract}
In the marine environment, track and dive parameter data (obtained using Argos or GPS tags and time-depth recorders) are commonly used to provide proxies for foraging behaviour of marine predators. However, their accuracy is rarely assessed. Recently, the addition of headmounted accelerometers has allowed for detection of prey capture attempts (PCAs) at sea, allowing for more accurate estimations of foraging behaviour. Despite increased numbers of such devices being deployed, their use is still marginal compared with other tools which measure track and dive parameters. The objectives of our study were (1) to identify the most relevant combination of tracking and diving metrics in predicting the frequency of PCAs in female southern elephant seals Mirounga leonina from the Kerguelen Islands, and (2) to apply it to a broader range of individuals for which only tracking and diving data were available. The results of our models were consistent with the optimal foraging theory as well as the optimal diving theory. The model with the best predictive performance was the one that combined both tracking and diving information. However, most of the variability in the number of PCAs could be solely explained by changes in the diving behaviour of seals. Finally, we used the best predictive model on 20 individuals, which had not been fitted with accelerometers, to determine their main foraging zones. The behavioural indicators established in this study constitute a useful ecological tool for population monitoring and conservation purposes.
\end{abstract}

KEY WORDS: Biologging · Dive parameters · Foraging - Prey capture events - Marine predator · Southern elephant seals $\cdot$ Track parameters

\section{INTRODUCTION}

Observations of the spatio-temporal variations in foraging effort or success of marine predators, particularly in those foraging at depth, are almost impossible. Over the last 3 decades, inferring such information from behavioural data, provided by a broad range of loggers deployed on seabirds, mammals and fish, has been one of the main objectives in biologging science. Hence, most variations in foraging behaviour of diving marine predators have been inferred from surface tracking and/or diving records (e.g. Bailleul et al. 2007b, 2008, Jonsen et al. 2007).

${ }^{*}$ Corresponding author: jadevacquiegarcia@gmail.com
In prey-aggregated environments such as the open ocean, predators usually use an area-restricted search (ARS) behaviour when encountering prey, reducing swimming speed and increasing sinuosity (Charnov 1976, Benhamou \& Bovet 1989). Thus, analyses of surface tracks, based on different methodologies - such as time spent in a given location (Bost et al. 1997), first passage time (FPT, Fauchald \& Tveraa 2003), or process-based models such as Hidden Markov Models (HMMs, Morales et al. 2004, Jonsen et al. 2007) - usually provide spatiotemporal information on the foraging zones. However, the sole assessment of foraging habitats from surface records is not always relevant, especially for

() The authors 2015. Open Access under Creative Commons by Attribution Licence. Use, distribution and reproduction are unrestricted. Authors and original publication must be credited. 
diving predators (Weimerskirch et al. 2007, Bailleul et al. 2008, Bastille-Rousseau et al. 2010). Additional information such as diving behaviour is often required to investigate foraging behaviour of such predators.

At depth, diving predators are generally assumed to reduce time spent descending or ascending, while spending more time at the bottom of their dive and increasing 'wiggles' when prey are encountered (Mori 1998). Thus, dive analyses and classifications (e.g. Fedak et al. 2001, Thums et al. 2008) based on their time-depth profiles or the calculation of different metrics (such as dive duration, bottom duration, wiggles, descent and ascent rate) (e.g. Croxall et al. 1985, Fedak et al. 2001, Thums et al. 2008) or first bottom time (Bailleul et al. 2008) have been sometimes used to discriminate between foraging, transiting or resting behaviours. But again, although being pertinent at large spatial scales, the methods derived from diving behaviour records can be inaccurate or misleading regarding the real identification of foraging events.

Therefore, although both tracking and diving data are undeniably useful for identifying foraging behaviour (Dragon et al. 2012) and produce comparable results, they cannot identify 'real' foraging success. Moreover, these proxies generally only provide qualitative information on the foraging activity (i.e. binary information: foraging vs. non-foraging). Despite the fact that the large community of marine ecologists recognizes these points, no study has evaluated the relative contribution of these 2 components (i.e. tracking vs. diving records) in predicting the variations in foraging success.

The recent development of other technologies, particularly oesophageal and stomach temperature sensors (Wilson et al. 1992), Hall sensors or accelerometers (Wilson et al. 2002, Suzuki et al. 2009, Viviant et al. 2010, Guinet et al. 2014), as well as video cameras (Bowen et al. 2002, Davis et al. 2003), is leading to a new stage in the understanding of successful foraging behaviour of marine predators. Indeed, these loggers are focused on measuring prey capture attempts (PCAs), which is currently considered as the best proxy for foraging success (see Guinet et al. 2014 where prey encounter events [PEE] correspond to PCA). However, the aforementioned devices may also have some restrictions. They cannot be used to distinguish between real prey captures and missed attempts, are generally deployed on a limited number of individuals in the field due to high costs, and the large amounts of data may be difficult to record due to limitations in memory as well as battery life.
Nevertheless, they provide the possibility to investigate how variations in movement and diving behaviour can be used to predict variations in foraging behaviour of a diving marine predator.

In this context, we used head-mounted accelerometers on female elephant seals from the Kerguelen Islands in addition to tracking and diving recorders to develop a model to predict variations in the number of PCAs performed by female seals in the open ocean (>1000 m depth), using track and dive metrics. Then, to illustrate the model, we applied the best predictive model to a broader range of individuals for which only tracking and diving data were available in order to define the main foraging zones of female elephant seals from the Kerguelen Islands. To be able to evaluate the effect of the time scale considered in predictions and applications, we chose to carry out this work on 2 scales, namely the dive scale and the $24 \mathrm{~h}$ scale. Kerguelen elephant seals were chosen as study models due to their incredible capacity to dive deeply and almost continuously during their long foraging trips through the Southern Ocean (McConnellet al. 1992). They were also chosen due to the large number of studies carried out on them on the Kerguelen Islands during the last $10 \mathrm{yr}$, leading to a large dataset on tracking and diving behaviour for this species.

\section{MATERIALS AND METHODS}

\section{Deployment of devices and data collection}

Thirty-two post-breeding female elephant seals were captured at the Kerguelen Islands $\left(49^{\circ} 20^{\prime} \mathrm{S}\right.$, $70^{\circ} 20^{\prime} \mathrm{E}$ ) between 2008 and 2012. Individuals were anesthetised using a 1:1 combination of tiletamine and zolazepam (Zoletil 100), which was injected intravenously (McMahon et al. 2000). Individuals were then equipped with 1 of 4 instrument combinations (Table 1). Seven seals were solely equipped with a SPLASH-10 logger (Wildlife Computers). In these tags, dive depth is collected and archived every second, while locations are estimated by the orbiting Argos satellites and then transmitted to the user. In addition, a GPS onboard system integrated into these tags allows collecting and archiving of animal locations. Thirteen other individuals were equipped with a conductivity-temperature-depth-satellite-related data logger (CTD-SRDL, Sea Mammal Research Unit, University of St Andrews), and an additional timedepth recorder (TDR-MK9, Wildlife Computers). As with the Splash-10 logger, locations are estimated by 
Table 1. Combinations of electronic devices deployment on 32 elephant seals. CTD-SRDL: conductivity-temperaturedepth-satellite relayed data logger; SPLASH-10: SPLASH-10 tags; TDR-MK9: time-depth recorder; TDR-MK10-X: timedepth recorder combined with an accelerometer

\begin{tabular}{|c|c|c|c|c|}
\hline Seal ID & $\begin{array}{l}\text { CTD- } \\
\text { SRDL }\end{array}$ & $\begin{array}{c}\text { SPLASH- } \\
10\end{array}$ & $\begin{array}{l}\text { TDR- } \\
\text { MK9 }\end{array}$ & $\begin{array}{c}\text { TDR- } \\
\text { MK10-X }\end{array}$ \\
\hline 2008-8 & & $\mathrm{X}$ & & \\
\hline 2009-1 & $\mathrm{X}$ & & $\mathrm{X}$ & \\
\hline 2009-10 & & $\mathrm{X}$ & & \\
\hline 2009-11 & & $\mathrm{X}$ & & \\
\hline 2009-2 & $\mathrm{X}$ & & $\mathrm{X}$ & \\
\hline 2009-3 & $\mathrm{X}$ & & $X$ & \\
\hline $2009-4$ & $\mathrm{X}$ & & $\mathrm{X}$ & \\
\hline $2009-5$ & & $\mathrm{X}$ & & \\
\hline $2009-6$ & & $\mathrm{X}$ & & \\
\hline 2009-8 & $\mathrm{X}$ & & $\mathrm{X}$ & \\
\hline 2009-9 & & $\mathrm{X}$ & & \\
\hline 2010-11 & $X$ & & $X$ & \\
\hline 2010-13 & $\mathrm{X}$ & & $\mathrm{X}$ & \\
\hline 2010-15 & $\mathrm{X}$ & & $X$ & \\
\hline $2010-20$ & & $\mathrm{X}$ & & \\
\hline $2010-8$ & $\mathrm{X}$ & & $\mathrm{X}$ & \\
\hline $2010-9$ & $\mathrm{X}$ & & $\mathrm{X}$ & \\
\hline 2011-13 & $\mathrm{X}$ & & $\mathrm{X}$ & \\
\hline 2011-15 & $\mathrm{X}$ & & $\mathrm{X}$ & \\
\hline 2011-19 & $\mathrm{X}$ & & $\mathrm{X}$ & \\
\hline 2010-18 & & $X$ & & $\mathrm{X}$ \\
\hline 2010-19 & & $\mathrm{X}$ & & $\mathrm{X}$ \\
\hline $2010-21$ & & $\mathrm{X}$ & & $\mathrm{X}$ \\
\hline 2011-14 & $\mathrm{X}$ & & & $\mathrm{X}$ \\
\hline 2011-16 & & $\mathrm{X}$ & & $\mathrm{X}$ \\
\hline 2011-17 & $\mathrm{X}$ & & & $\mathrm{X}$ \\
\hline 2011-18 & & $\mathrm{X}$ & & $\mathrm{X}$ \\
\hline 2011-21 & & $\mathrm{X}$ & & $\mathrm{X}$ \\
\hline 2011-22 & $\mathrm{X}$ & & & $\mathrm{X}$ \\
\hline $2011-26$ & & $\mathrm{X}$ & & $\mathrm{X}$ \\
\hline $2011-27$ & & $\mathrm{X}$ & & $\mathrm{X}$ \\
\hline $2011-28$ & & $\mathrm{X}$ & & $\mathrm{X}$ \\
\hline
\end{tabular}

the orbiting Argos satellites, and the dive depth is recorded and archived every second in TDR-MK9 tags. Finally, 9 females were equipped with a combination of a SPLASH-10 and a TDR-accelerometer (TDR-MK10-X, Wildlife computers), while 3 individuals were equipped with CTD-SRDLs and TDR-accelerometers. TDR-accelerometers sampled 16 accelerations per second $(16 \mathrm{~Hz})$ on 3 axes: longitudinal (surge), vertical (heave) and lateral (roll). The acceleration measured simultaneously on these 3 axes was used to detect prey capture attempts.

Data loggers were glued on the heads of the seals using quick-setting epoxy (Araldite AW 2101, Ciba), after cleaning the fur with acetone. Upon returning from their post-breeding foraging trip after 65 to $80 \mathrm{~d}$, females were located on land via the Argos data, recaptured, and the electronic devices recovered.

\section{Data processing}

Tracking and diving data

The time-depth records (SPLASH10, TDR-MK9 or TDR-MK10-X) of the 32 seals were analysed using a custom-written MATLAB code (Matlab v.7.0.1, code available on request) in order to calculate dive metrics to be included into models. A dive was considered as an excursion performed in the open ocean (>1000 m depth) which was deeper than $15 \mathrm{~m}$ (Guinet et al. 2014). Then, each of the detected dives was divided into 3 distinct phases based on a cubic polynomial function fitted on their time-depth records. The descent and ascent phases were defined as the time periods when the absolute vertical speed $(\delta z / \delta t)$ (obtained every second, calculated from the ratio between the depth [z] difference and the time [t] difference and from the polynomial fit of the dive) exceeded $0.75 \mathrm{~m} \mathrm{~s}^{-1}$. The bottom phase was defined as the period between the descent and the ascent phases. Eight different dive metrics were then calculated: maximum depth (m), bottom duration (s), postdive surface duration (s), vertical sinuosity in the bottom phase (no unit), ascent rate $\left(\mathrm{m} \mathrm{s}^{-1}\right)$, descent rate $\left(\mathrm{m} \mathrm{s}^{-1}\right)$ (see Dragon et al. 2012 for details), bottom slope $\left(\mathrm{m} \mathrm{s}^{-1}\right)$, which corresponds to the slope of the bottom phase (i.e. the absolute slope coefficient of the linear regression fitted on the time-depth values in this phase) and depth variability in the bottom phase $(\mathrm{m})$, which is the standard error of the depth values during the bottom phase (Table 2).

Track metrics were also calculated using a customwritten MATLAB code (Matlabv.7.0.1, code available on request) after locations were filtered by manually removing aberrant locations and then by using a switching-state-space model (Jonsen et al. 2007, Dragon et al. 2012). Spatial coordinates (Lon-Lat) were allocated to each dive by linear interpolation between 'true' locations provided by the Argos or GPS tags. Two different track metrics were then calculated from dive location: horizontal swimming speed $\left(\mathrm{m} \mathrm{s}^{-1}\right)$ (i.e. ratio of distance to time between 2 successive dives) and turning angles (degrees) (Table 2). Finally, solar elevation (degrees), determined using the 'suncycle' function in MATLAB, was calculated as an external metric to each dive based on their location and the time they occurred. This solar elevation provides an indication of the day period (i.e. dawn, day, dusk or night) (Table 2).

At the $24 \mathrm{~h}$ scale, all dive and track metrics were either averaged (horizontal swimming speed, turning angles, vertical sinuosity, ascent rate, descent rate, 
Table 2. Description of the calculation of track, dive and external metrics at the dive and $24 \mathrm{~h}$ scales

\begin{tabular}{|c|c|c|c|}
\hline Metrics & Description at the dive scale & Unit & $\begin{array}{l}\text { Description at the } \\
24 \mathrm{~h} \text { scale }\end{array}$ \\
\hline \multicolumn{4}{|l|}{ Dive metrics } \\
\hline Maximum depth & Maximum depth of the dive & $\mathrm{m}$ & Summed over $24 \mathrm{~h}$ \\
\hline Bottom duration & Duration of the bottom phase of the dive & $\mathrm{s}$ & Summed \\
\hline Post-dive surface duration & Duration of the following surface phase of the dive & $\mathrm{s}$ & Summed \\
\hline $\begin{array}{l}\text { Vertical sinuosity during } \\
\text { bottom phase }\end{array}$ & $\begin{array}{l}\text { Ratio between the total distance swum at the bottom and } \\
\text { the sum of the Euclidian distances from the depth at the } \\
\text { beginning of the bottom phase to the max. depth and from } \\
\text { the max. depth to the depth at the end of the bottom phase }\end{array}$ & no unit & Averaged over $24 \mathrm{~h}$ \\
\hline Ascent rate & $|\Delta \mathrm{z} / \Delta t|$ during the ascent phase of the dive (z: depth, $t:$ time) & $\mathrm{m} \mathrm{s}^{-1}$ & Averaged \\
\hline Descent rate & $|\Delta \mathrm{z} / \Delta t|$ during the descent phase of the dive (z: depth, $t:$ time $)$ & $\mathrm{m} \mathrm{s}^{-1}$ & Averaged \\
\hline Bottom slope & $\begin{array}{l}\text { Absolute slope coefficient of the linear regression fitted } \\
\text { to the time-depth values during bottom phase }\end{array}$ & $\mathrm{m} \mathrm{s}^{-1}$ & Averaged \\
\hline $\begin{array}{l}\text { Depth variability during } \\
\text { bottom phase }\end{array}$ & Standard error of the depth values during bottom phase & $\mathrm{m}$ & Averaged \\
\hline \multicolumn{4}{|c|}{ Track metrics } \\
\hline Horizontal swimming speed & Speed between the previous and the current dives & $\mathrm{m} \mathrm{s}^{-1}$ & Averaged \\
\hline Turning angle & $\begin{array}{l}\text { Turning angle between the previous, the current and } \\
\text { the following dives }\end{array}$ & degrees & Averaged \\
\hline \multicolumn{4}{|l|}{ External metrics } \\
\hline Solar elevation & Angle of the sun with the skyline & degrees & - \\
\hline Number of dives & - & No unit & Summed \\
\hline
\end{tabular}

bottom slope, variability in the bottom) or summed (maximum depth, bottom duration, post-dive surface duration), with the exception of solar elevation. The total number of dives over $24 \mathrm{~h}$ was also calculated as an additional metric (Table 2).

\section{Acceleration data}

Acceleration data from the 12 individuals equipped with a TDR-MK10-X tag were processed following Viviant et al. (2010) and Gallon et al. (2012) (customwritten MATLAB code, available on request). The procedureis described in detail in Guinet et al. (2014). Regardless of the axis, the recorded acceleration is composed of 2 types of acceleration: static and dynamic. The static acceleration is caused by the position of the gravity center of the animal compared with the gravity vector. The static acceleration corresponds to the low-frequency signals whereas dynamic acceleration is the acceleration generated by short movements of the body and/or the head of the animal. This acceleration is represented in the acceleration signal as high-frequency signals. Specifically, the acceleration records were processed firstly by filtering them on the 3 axes to remove 'noise' in the signal induced by swimming movement (static acceleration). Then, for each axis, significant peaks in acceleration were detected when standard deviation of acceleration values within a 5 s moving window surpassed a threshold. Such a threshold was determined for each axis using the function 'k-means' (tool box statistics, Matlab). Only significant peaks simultaneously detected on the 3 axes were considered as a PCA. A total number of PCAs was calculated per dive and over $24 \mathrm{~h}$.

\section{Data analyses and modelling process}

General approach

To develop a general model, at each scale, for predicting the variations in the number of PCAs of female seals using track and dive metrics, we first investigated, using the individuals equipped with accelerometers ( $\mathrm{n}=12$ ), how accurately the number of PCAs can be assessed by the combined use of track and dive data (explanatory models) (Fig. 1). Then, to identify the relative contribution of changes in track and dive behaviour to predict the variations in foraging performance, we tested and compared, on the same individuals, different models with either tracking data or diving data, and then the 2 metrics combined (predictive models). We did this at the 2 scales and then selected the best models to predict the number of PCAs per dive and per $24 \mathrm{~h}$ period (Fig. 1). Then, to illustrate the models, we applied the best predictive models to the broader range of individuals for which only track- 


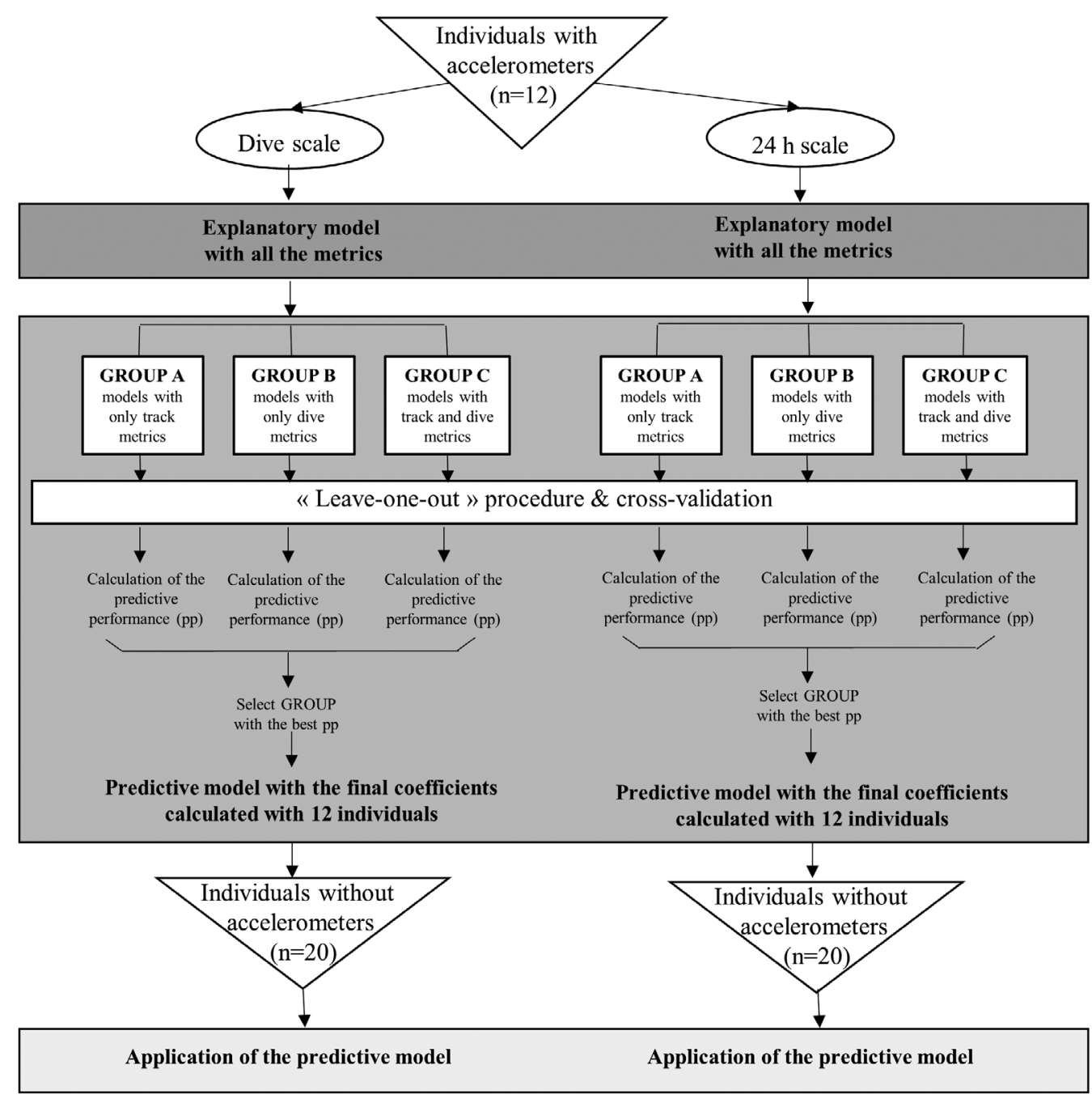

Fig. 1. Modelling process: creation of explanatory and predictive models at the dive and $24 \mathrm{~h}$ scale and their application

ing and diving data were available $(\mathrm{n}=20)$ in order to define the main foraging zones of the elephant seals from the Kerguelen Islands (Fig. 1).

\section{Relationship between PCAs and other foraging metrics (explanatory models)}

The relationship between the number of PCAs and track, dive and external metrics were investigated per dive and over $24 \mathrm{~h}$ on all the individuals equipped with an accelerometer ( $\mathrm{n}=12$ ) using generalized linear mixed models (GLMM) (package 'lme4' in R 2.10.1; R Development Core Team 2010). Metrics were first standardized (Zuuret al. 2007) after verifying that no correlation values between metrics exceeded a value of 0.8 . Models were fitted with a Poisson family distribution with individuals included as random intercepts to avoid the effects of the hierarchical structure of the data. All the combinations of metrics were tested and the models, at each scale, were ranked according to the corrected Akaike's information criterion, AICc (Burnham \& Anderson 2004); all models are listed in the Supplement at www.intres.com/articles/suppl/m541p265_supp.xls. The AICc weight of each model was calculated to represent the relative likelihood of the candidate models. The candidate models selected were those for which the cumulative sum of the AICc weight was greater than 0.95. If the analyses indicated more than 1 candidate model, a model-averaging procedure was conducted. This procedure takes into account all of the coefficients obtained by the selected models at each scale and calculates averaged coefficients in function of the AICc weight of each model (Burnham \& Anderson 2002). 

Predicting PCAs from other foraging
metrics (predictive models)

In order to identify the most relevant metrics to predict the number of PCAs per dive or over $24 \mathrm{~h}$, we considered 3 different groups of models-Group A: track and external metrics selected in explanatory models; Group B: dive and external metrics selected in explanatory models; Group C: all the metrics selected in explanatory models.

Using the modelling process previously described, for each group of the per dive and over $24 \mathrm{~h}$ scales, we tested all the possible combinations of metrics on all of the individuals equipped with accelerometers ( $\mathrm{n}=12$ ) minus one individual ('leave-oneout' procedure). Models were then selected according to their AICc weight as previously described. If the analyses indicated more than 1 candidate model, a model-averaging procedure was conducted to obtain averaged coefficients. The coefficients obtained for each group of the per dive and over $24 \mathrm{~h}$ scales were applied to the remaining individual to compare observed and predicted number of PCAs. The procedure was repeated in such a way that all the individuals were left out once (cross-validation). The predictive performance (pp) of the 6 groups ( 3 groups per scale) was assessed, using the following equation to compare all the observed and predicted number of PCA obtained for each individual left out:

$$
\mathrm{pp}=1-\frac{(\log \operatorname{lik}(m)-\log \operatorname{lik}(c))}{(\log \operatorname{lik}(m n)-\log \operatorname{lik}(c))}
$$

where $m$ represents the tested group, $m n$ corresponds to null models and $c$ to perfect models where the predicted number of PCAs of all the individuals left out are equal to the observed number of PCAs. 'Loglik' means log of likelihood. The closer to 1 the result is, the higher is the predictive performance of the group.

Model groups with the best predictive performance were selected at the dive and $24 \mathrm{~h}$ scales. Then they were fitted, with a model-averaging procedure, to the 12 individuals with accelerometers to obtained final coefficients required for a future application.

\section{Application}

The final coefficients were applied to all individuals that had not been equipped with an accelerometer $(n=20)$ to predict the number of PCAs per dive or over $24 \mathrm{~h}$ for female elephant seals from the Kerguelen Islands. To obtain a PCA rate (i.e. the number of PCAs per unit of time), this number was corrected by the dive duration or the summed dive duration at the dive or $24 \mathrm{~h}$ scale, respectively.

\section{RESULTS}

\section{General results}

The 12 female elephant seals equipped with accelerometers spent (mean $\pm \mathrm{SD}$ ) $71 \pm 23 \mathrm{~d}$ at sea. However, 6 devices failed after $10 \pm 4$ d. A total of 27877 dives (data collected by the 6 devices that prematurely failed included) were analysed. Of this total, $23597(85 \%)$ contained at least 1 PCA. The mean number of PCAs per dive was $8 \pm 7$ (range 0 to 55). For all individuals, a total of $442 \mathrm{~d}$ were analysed. The cumulative number of PCAs over $24 \mathrm{~h}$ was $500 \pm 259$ (range 0 to 1771). Female elephant seals performed $63 \pm 13$ dives over $24 \mathrm{~h}$.

\section{Relationship between PCAs and other foraging metrics (explanatory models)}

At both time scales, a model-averaging procedure was conducted. All metrics tested were found to correlate with the number of PCAs and defined as candidates for the predictive models (Table 3 ).

At the dive scale, the relationship was positive for the following metrics in order of importance: ascent 
Table 4. Predictive performances (see Eq. 1) of the 3 groups of models at each scale. Group A: models composed using track and external metrics; Group B models composed using dive and external metrics; Group C models composed using all the metrics combined. The predictive performances of the best groups at each scale are in bold

\begin{tabular}{|lccc|}
\hline & Group A & Group B & Group C \\
\hline Dive scale & 0.018 & 0.215 & $\mathbf{0 . 2 1 7}$ \\
24 h scale & 0.194 & 0.751 & $\mathbf{0 . 7 6 4}$ \\
\hline
\end{tabular}

rate, descent rate, vertical sinuosity during the bottom phase, turning angles, solar elevation and bottom duration. The relationship was negative, in order of importance, for post-dive surface duration, maximum depth, horizontal swimming speed, depth variability at the bottom and bottom slope.

At the $24 \mathrm{~h}$ scale, the relationship was positive for the following metrics in order of importance: bottom duration, maximum depth, post-dive surface duration, vertical sinuosity during the bottom phase, the total number of dives, turning angles, ascent rate, depth variability in the bottom phase and bottom slope. The relationship was negative, in order of importance, for horizontal swimming speed and descent rate.

\section{Predicting PCAs from other foraging metrics (predictive models)}

The predictive performances of the groups (A, B and $C$ ) are summarised in Table 4 and detailed in Fig. 2 for both scales. In each case, the group of models that included all metrics (i.e. Group C) had the best predictive performance. Dive metrics contributed more to predictive performance than track metrics.

\section{Application}

Measured and predicted foraging zones of southern elephant seals are shown in Fig. 3. Fig. 3A,C show the measured rate of PCAs and tracks of the
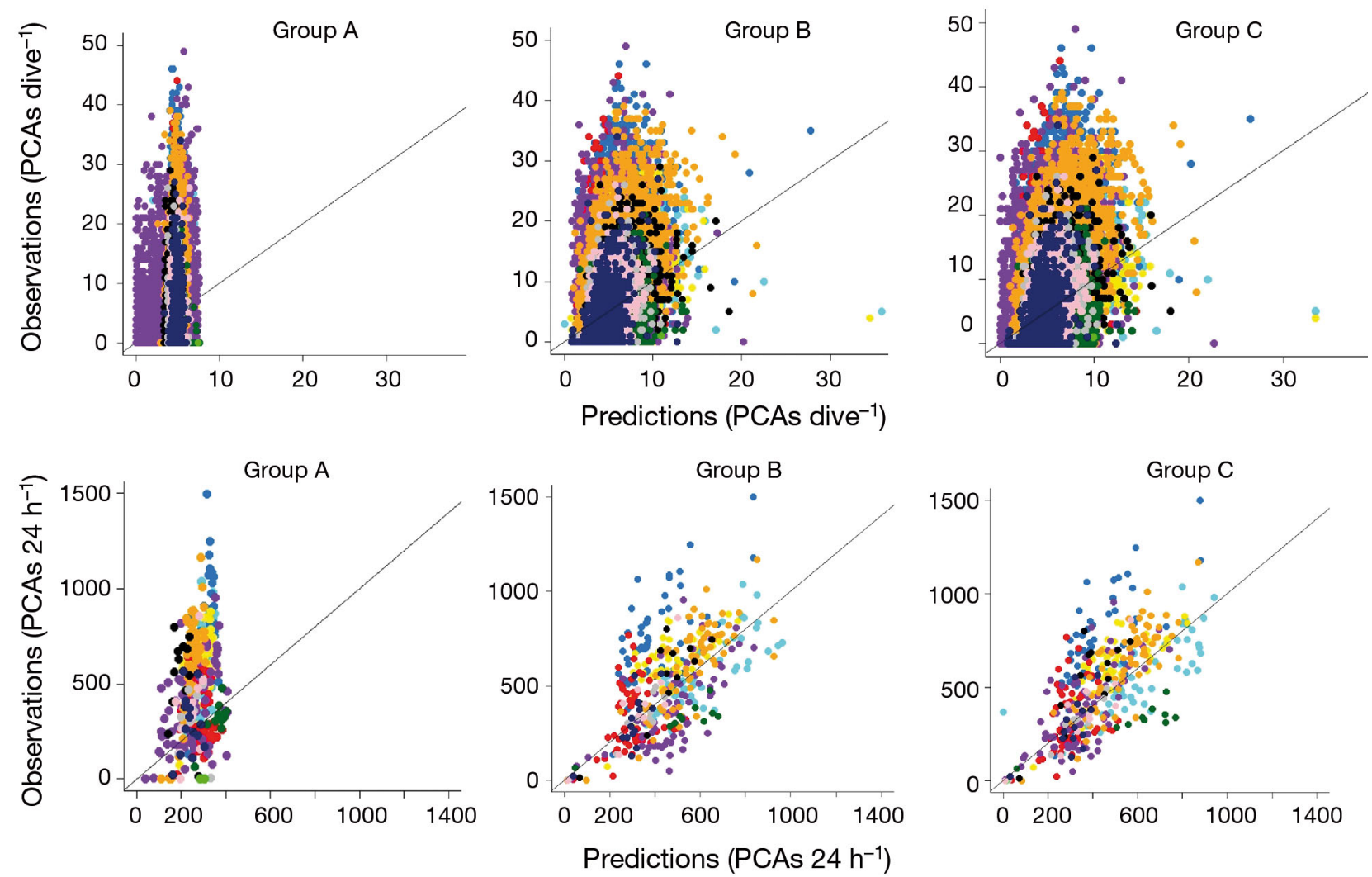

Fig. 2. Observed number of prey catch attempts (PCAs) versus the predicted number of PCAs at both time scales female southern elephant seals, obtained from the 12 individuals equipped with accelerometers and using the 'leave-one-out' procedure. At the dive scale, each dot represents a dive. At the $24 \mathrm{~h}$ scale, each dot corresponds to a $24 \mathrm{~h}$ period. Each colour corresponds to a different individual. Group A: models composed using track and external metrics; Group B models composed using dive and external metrics; Group C models composed using all the metrics combined 
individuals equipped with accelerometers ( $\mathrm{n}=12$ ). Final coefficients obtained from the predictive models at both scales were then applied to the individuals that had not been equipped with accelerometers ( $\mathrm{n}=20$ ), to predict the number of PCAs that occurred along their tracks. Fig. 3B,D show the rate of predicted PCAs and tracks of these individuals. These individuals spent on average $( \pm \mathrm{SD}) 74.8 \pm 15.3 \mathrm{~d}$ at sea and performed $64 \pm 14$ dives per $24 \mathrm{~h}$. A total of 99228 dives of the 20 seals with accelerometers were analysed. The mean predicted number of PCAs per dive was $5 \pm 11$ (range 0 to 50 with 12 extreme values). For all individuals, a total of 1476 periods of $24 \mathrm{~h}$ were identified and analysed. The cumulative predicted number of PCAs over $24 \mathrm{~h}$ was $446 \pm 576$ (range 6 to 4735 ). One $24 \mathrm{~h}$ period of a single track with over 20000 predicted PCAs was removed from the analysis.

\section{DISCUSSION}

In agreement with previous studies, we found that track information such as travelling speed and track sinuosity provide insight into variation of prey capture attempts rate (Knoppien \& Reddingius 1985, Kareiva \& Odell 1987, Benhamou \& Bovet 1989, Fauchald \& Tveraa 2003). However, the main finding of our study was that, in female southern elephant seals, most of the variability in prey capture attempts

\section{Dive scale}

\section{A) Individuals with accelerometers}

$$
\mathrm{n}=12
$$
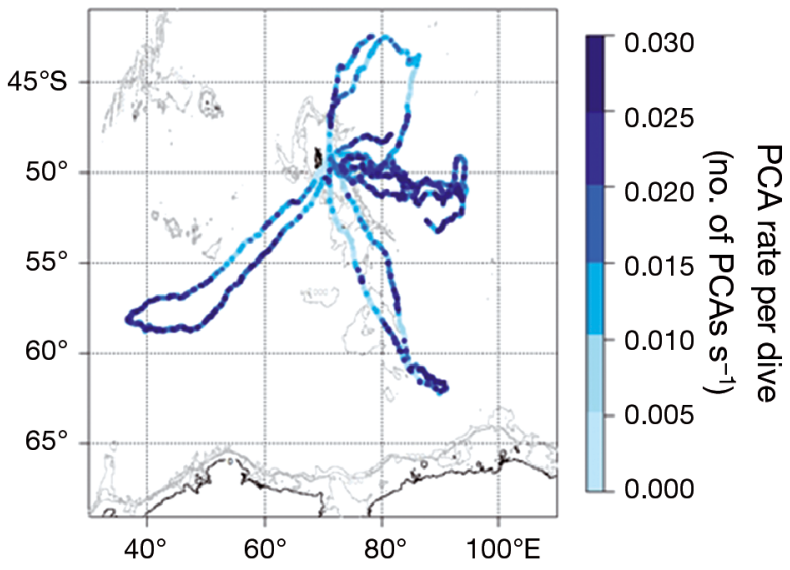

0.000

$24 \mathrm{~h}$ scale

C) Individuals with accelerometers

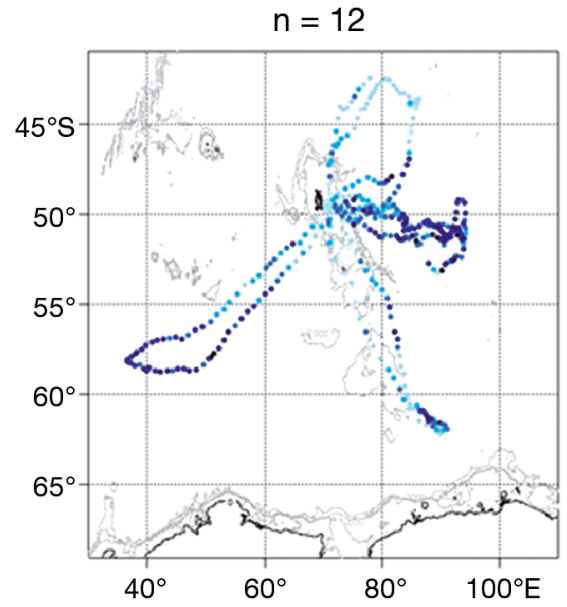

B) Individuals without accelerometers

$$
n=20
$$

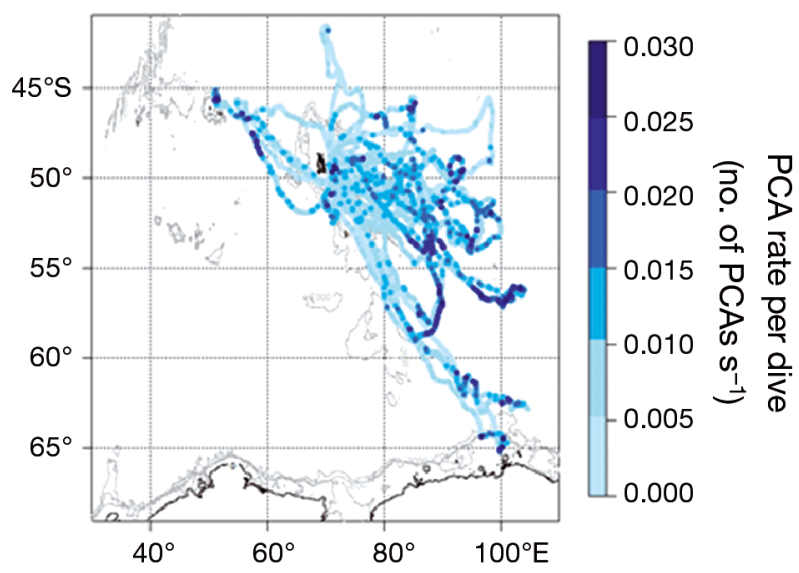

D) Individuals without accelerometers

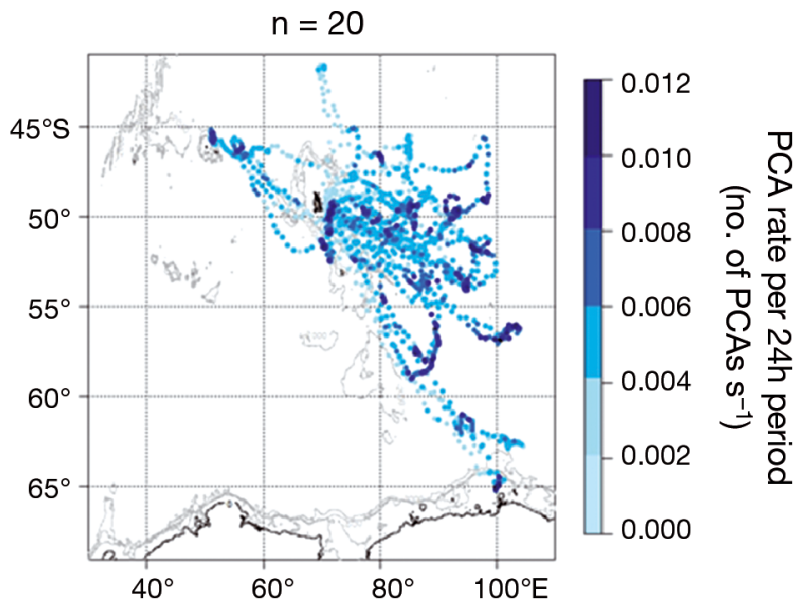

Fig. 3. Foraging behaviour (prey capture attempt [PCA] rate) of southern elephant seals. Each dot corresponds to (A,B) a dive or $(C, D)$ a $24 \mathrm{~h}$ period. $(A, C)$ Foraging behaviour measured on the 12 individuals with accelerometers. (B,D) Predicted foraging behaviour (estimated for the 20 individuals that had not been equipped with accelerometers) using Group $\mathrm{C}$ models 
rate is best explained by changes in diving behaviour. As a consequence, the predictive models of PCA containing diving information (derived from Group B) were nearly as powerful as those combining both tracking and diving data (derived from Group C) while predictive performances of models built using only tracking data (derived from Group A) were comparatively poor. Predictive models built from diving data had a predictive value nearly 4 times as high as those based on tracking data alone.

\section{Relationship between PCAs and other foraging metrics (explanatory models)}

The number of PCAs was found to be related to all track and dive metrics tested, at both scales. These findings are consistent with previous studies on elephant seals, which suggested that changes in movement (sinuosity and horizontal speed) and diving behaviour could be related to a change in body condition (Thums et al. 2011, Dragon et al. 2012), and therefore potential food intake.

Elephant seals were found to reduce their traveling speed and increase their track sinuosity when encountering more prey items at the 2 time-scales. This result is in accordance with the predictions stating that, in a prey-aggregated environment such as the open ocean, a predator should intensify its foraging activity in a productive patch (Kareiva \& Odell 1987), decreasing horizontal speed and increasing horizontal sinuosity (Benhamou \& Bovet 1989).

At the dive scale, the number of PCAs increased when seals increased their bottom time, which is in accordance with the Optimal Diving Theory (Gentry \& Kooyman 1986, Houston \& Carbone 1992, Thompson et al. 1993, Carbone \& Houston 1996) and consistent with the fact that diving predators mainly forage during the bottom phase of a dive (Wilson et al. 2002, Fossette et al. 2008, Guinet et al. 2014). The number of PCAs also increased when seals increased their bottom vertical sinuosity. This last finding reveals that when encountering prey during the bottom phase of pelagic dives, elephant seals do not swim at a constant depth, but continuously zig-zag up and down, suggesting that they are actively foraging within the patch of prey (Thompson et al. 1993). Elephant seals were also more successful when remaining at the same general depth and exhibiting lower depth variability during the bottom phase of their dive. This relationship, obtained at the dive scale, suggests that seals are more successful when encountering prey structured in a discrete patch over a narrow depth thickness. These discrete patches could be related to changes in oceanographic conditions down the water column, creating marked prey habitat boundaries, as discussed in McIntyre et al. (2014). Many fish species, including myctophids (which are a major prey item for elephant seals (Slip 1995, Daneri \& Carlini 2002, Cherel et al. 2008) are particularly sensitive to temperature regimes and are limited to a surprisingly narrow thermal niche (Beitinger \& Fitzpatrick 1979, Hulley 1990).

The number of PCAs decreased with increasing diving depth at the dive scale. This result suggests that prey density decreases with increasing depth, consistent with a decrease in biomass with depth (Williams \& Koslow 1997). A decrease in bioluminescence events (considered as an indicator of prey) with increasing depth (Vacquié-Garcia et al. 2012) also supports this theory. Given the results of our model, shallow dives lead more often to several PCAs. In contrast, deep dives may lead to a low number of PCAs. It is possible that the nutritional value of prey captured at depth may be significantly higher than that of prey captured in shallow areas (Thumset al. 2011).

Both descent and ascent rates were found to increase in dives where we detected PCAs. These results suggest that seals adjust their transit rates (by modifying their dive pitch [diving at steeper angle] and/or their swimming activity) according to their foraging success: they rise to the surface and anticipate their future foraging success by increasing their descent rate in order to return rapidly to the prey patch, as found in other species such as the fur seal Arctocephalus gazella (Viviant et al. 2014).

Surface duration following a dive was negatively related to increasing numbers of PCAs. This finding is counter-intuitive as seals foraging successfully during a dive exhibit a higher swimming effort ( $\mathrm{J}$. Joffrey pers. comm.) and should, therefore, spend more time at the surface to recover. Our results suggest that after a successful dive, seals tend to decrease their surface time to return to depth more rapidly and maximize foraging opportunities. This type of finding is consistent with those reported for king penguins (Hanuise et al. 2010).

A change in sign of the relationships between the models at the dive scale and the $24 \mathrm{~h}$ scale was observed for 5 parameters: maximum depth, postdive surface duration, descent rate, bottom slope and depth variability at the bottom. Maximum depth was found to have a negative effect at the dive scale, but cumulative depth over a $24 \mathrm{~h}$ period was found to be positively related to the number of PCAs performed. 
A negative relationship between surface interval and the number of PCAs was detected at the dive scale, but a positive relationship was detected between the number of PCAs and the cumulative surface duration at the $24 \mathrm{~h}$ scale. Furthermore, while descent rate was found to have a positive effect on the number of PCAs at the dive scale, a negative effect was detected at the $24 \mathrm{~h}$ scale. These changes in sign suggest that on a $24 \mathrm{~h}$ scale, elephant seals are more successful when they perform a greater number of shallower and shorter dives compared to longer and deeper dives. Indeed, an increase in dive duration with diving depth is a common trait found in all diving predators. As a consequence, when performing a greater number of shallower and shorter dives over $24 \mathrm{~h}$, the cumulative depth (i.e. the total vertical distance covered) as well as the total amount of time spent at surface, increased compared to when seals were performing deeper and longer dives. Consistently, mean descent rate tended to increase with increasing diving depth in king penguins (Hanuise et al. 2010) but also elephant seals (L. Yves pers. comm.). Therefore, when performing shallower dives, seals should on average exhibit a lower mean descent rate compared with times when they dive deeper to reach prey. The relationships of bottom slope and depth variability at the bottom with the number of PCAs were negative at the dive scale but became positive and marginally significant at the $24 \mathrm{~h}$ scale. This change in sign remains difficult to interpret. Interestingly, when considering the cumulative dive depth and its variability, seals performed a greater number of PCAs when diving shallower with a lower variability of their diving depth, indicating that elephant seals were more successful when encountering prey closer to the surface, and over a limited range of depths.

\section{Predicting PCAs from other foraging metrics (predictive models)}

In recent decades, a growing number of analytical methods have been developed to infer preferred foraging areas from tracking data (Benhamou \& Bovet 1989, Fauchald \& Tveraa 2003 among others). Our study indicates that the relationships existing between the number of PCAs and tracking data are consistent with the theoretical predictions (Kareiva \& Odell 1987). However, the predictive performances of the track-only based models (Group A) tended to be negligent at the dive scale $(\mathrm{pp}=0.018)$ and remained poor at the $24 \mathrm{~h}$ scale $(\mathrm{pp}=0.194)$ (Table 3$)$.
The use of dive metrics improved the predictive power of models (Group B) (pp $=0.215$ at the dive scale and $\mathrm{pp}=0.751$ at the $24 \mathrm{~h}$ scale), indicating that the change in dive behaviour provides a more powerful insight in the variation of the number of PCA of the seals than the horizontal spatial behaviour. Therefore, existing dive data recorded along the track of these predators can be used to assess more precisely the variation in foraging behaviour of seals, compared with analyses of track data alone. Timedepth dive profiles are transmitted at different resolutions by an increasing number of satellite-relayed data loggers, and this information may prove to be highly valuable to better assess the spatio-temporal variation of the foraging behaviour of these predators, and possibly other diving predators such as fur seals or king penguins. As expected, the inclusion of track metrics with the dive metrics at the 2 scales improved the predictive power of both models, but this effect was marginal ( $\mathrm{pp}=0.217$ at the dive scale and $\mathrm{pp}=0.764$ at the $24 \mathrm{~h}$ scale). This result emphasizes the importance of dive metrics when assessing spatio-temporal variation of foraging behaviour. The fact that the track data alone does not correctly predict the foraging behaviour of animals is not surprising. Indeed, other studies have emphasized the limitations of track data and the usefulness of diving data when measuring variations in foraging performance in deep-diving predators ('first bottom time', Bailleul et al. 2008). Considering the low number of predictors used, the predictive performance of the selected groups at each scale (Group C) can be considered as low at the dive scale $(\mathrm{pp}=0.217)$ and $\operatorname{good}(\mathrm{pp}=$ 0.764 ) at the $24 \mathrm{~h}$ scale at predicting the number of PCAs (Table 4). We can explain the good predictive performance of the Group C model at the $24 \mathrm{~h}$ scale by the fact that all the parameters are averaged or summed over $24 \mathrm{~h}$. In the model derived from Group $\mathrm{C}$ at this scale, the results combine day and night foraging strategies, smoothing all dive recovery times and chances of foraging. In contrast, the model derived from Group $\mathrm{C}$ at the dive scale exhibits significantly more scatter because it forces integration of day and night foraging patterns, which are mostly different (Hindell et al. 1991, McIntyre et al. 2010). Change of the predictive power according to the time scale considered should, in future, be investigated at different time intervals, separating dives into day and night. All 12 individuals equipped with accelerometers showed low and good predictions for Group C model at each scale (Fig. 2). Models derived from this group, at the $24 \mathrm{~h}$ scale, were capable of predicting the foraging activity of new individuals based on 
their diving patterns only and the predictions were only marginally improved when adding tracking data. It is important to note that the models derived from Group C at each scale were developed for female elephant seals foraging in pelagic waters of the Southern Ocean and their applicability to other species or regions remains to be tested. Testing models on female northern elephant seals would assist in assessing their generic value, as these animals forage pelagically and some individuals are already equipped with accelerometers detecting PCAs.

\section{Application}

When applying the models derived from Group C at the 2 scales to the 20 individuals for which we had only track and dive data, we observed a main foraging zone east of Kerguelen (Fig. 3). The Crozet area and the edges of the Antarctic plateau also emerged as important foraging zones. This coincides with areas where it has been reported that the body condition of seals has improved (Biuw et al. 2007, Bailleul et al. 2007b). The improvement of the predictive performances of foraging behaviour using dive data should allow for more precise assessments of inter-annual variation in the foraging behaviour of elephant seals. Further, improved predictive performance may provide insights into possible relationships between local oceanographic conditions and foraging patterns. However, while this approach can be used to locate areas of favourable foraging, it does not provide information on the quality (size and energetic content) of the prey. A given PCA, in the case where this PCA is associated to a real capture or ingestion, may correspond to very different prey items, since elephant seals are known to take a variety of prey items, from squid to fish (e.g. Rodhouse et al. 1992, Slip 1995, Daneri \& Carlini 2002, Cherel et al. 2008, Naito et al. 2013).

\section{CONCLUSIONS}

The combination of track and dive behavioural variables enables prediction of the number of PCAs of female southern elephant seals with a reasonable level of confidence, thereby providing quantitative measurements of their foraging behaviour. This approach may therefore constitute a useful ecological tool for population monitoring or conservation purposes (Morris et al. 2009). In addition, the tools used to obtain these variables are less expensive than accelerometers and can more easily be applied on a large number of individuals. The use of behavioural variables to assess foraging activity allows for a better understanding of foraging ecology of diving marine predators with a new emphasis on prey distribution through the oceans and/or on the relationship between foraging efficiency and environmental conditions. It also provides an unprecedented opportunity to re-examine/re-analyse old datasets leading to new perspectives in long-term studies of foraging ecology of such predators.

Acknowledgements. The authors thank all the colleagues and volunteers involved in the field work on southern elephant seals at the Kerguelen Islands, with special acknowledgement of the invaluable field contribution of G. Bessigneul and A. Chaigne. This work was supported by the ANR Topp-Patches, ANR Mycto- 3D-Map, the CNES-TOSCA and the Total Foundation. We are indebted to IPEV (Institut Polaire Français), for financial and logistical support of Antarctic research program 109 (Seabirds and Marine Mammal Ecology led by H. Weimerskirch). Special thanks also go to Pascal Monestiez and Kevin Le Rest (CEBC CNRS) for their helpful advice at the different stages of the manuscript. Finally, the authors also thank Lauren Biermann for her help with English editing.

\section{LITERATURE CITED}

Bailleul F, Charrassin JB, Monestiez P, Roquet F, Biuw M, Guinet C (2007b) Successful foraging zones of southern elephant seals from the Kerguelen islands in relation to oceanographic conditions. Philos Trans R Soc Lond B Biol Sci 362:2169-2181

Bailleul F, Pinaud D, Hindeel M, Charassin JB, Guinet C (2008) Assessment of scale-dependent foraging behaviour in southern elephant seals incorporating the vertical dimension: a development of the First Passage Time method. J Anim Ecol 77:948-957

Bastille-Rousseau G, Fortin D, Dussault C (2010) Inference from habitat-selection analysis depends on foraging strategies. J Anim Ecol 79:1157-1163

Beitinger TL, Fitzpatrick LC (1979) Physiological and ecological correlates of preferred temperature in fish. Integr Comp Biol 19:319-329

> Benhamou S, Bovet P (1989) How animals use their environment: a new look at kinesis. Anim Behav 38:375-383

- Biuw M, Boehme L, Guinet C, Hindell M and others (2007) Variations in behavior and condition of a Southern Ocean top predator in relation to in situ oceanographic conditions. Proc Nat Acad Sci USA 104:13705-13710

> Bost CA, Georges JY, Guinet C, Cherel Y and others (1997) Foraging habitat and food intake of satellite-tracked king penguins during the austral summer at Crozet Archipelago. Mar Ecol Prog Ser 150:21-33

Bowen WD, Tully D, Boness DJ, Bulheier BM, Marshall GJ (2002) Prey-dependent foraging tactics and prey profitability in a marine mammal. Mar Ecol Prog Ser 244:235-245

Burnham KP, Anderson DR (2002) Model selection and multimodel inference: a practical information theoretic approach. Springer, New York, NY 
Burnham KP, Anderson DR (2004) Multimodel inference: understanding AIC and BIC in model selection. Sociol Methods Res 33:261-304

Carbone C, Houston AI (1996) The optimal allocation of time over the dive cycle: an approach based on aerobic and anaerobic respiration. Anim Behav 51:1247-1255

> Charnov EL (1976) Optimal foraging, the marginal value theorem. Theor Popul Biol 9:129-136

Cherel Y, Ducatez S, Fontaine P, Richard P, Guinet C (2008) Stable isotopes reveals the trophic position and mesopelagic diet of female southern elephant seals breeding on the Kerguelen Islands. Mar Ecol Prog Ser 370:239-247

> Croxall JP, Everson I, Kooyman GL, Ricketts C, Davis RW (1985) Fur seal diving behavior in relation to vertical distribution of Krill. J Anim Ecol 54:1-8

Daneri GA, Carlini AR (2002) Fish prey of southern elephant seals, Mirounga leonina, at King George Island. Polar Biol 25:739-743

> Davis RW, Fuiman LA, Williams TM, Horning M, Hagey W (2003) Classification of Weddell seal dives based on 3 dimensional movements and video-recorded observations. Mar Ecol Prog Ser 264:109-122

> Dragon AC, Bar-Hen A, Monestiez P, Guinet C (2012) Horizontal and vertical movements as predictors of foraging success in a marine top-predator. Mar Ecol Prog Ser 447:243-257

Fauchald P, Tveraa T (2003) Using first-passage time in the analysis of area-restricted search and habitat selection. Ecology 84:282-288

Fedak MA, Lovell P, Grant SM (2001) Two approaches to compressing and interpreting time-depth information as collected by time-depth recorders and satellite-linked data recorders. Mar Mamm Sci 17:94-110

Fossette S, Gaspar P, Handrich Y, Le Maho Y, Georges JY (2008) Dive and beak movement patterns in leatherback turtles Dermochelys coriacea during internesting intervals in French Guiana. J Anim Ecol 77:236-246

Gallon S, Bailleul F, Charrassin JB, Guinet C, Bost CA, Handrich Y, Hindell M (2012) Identifying foraging events in deep diving southern elephant seals, Mirounga leonina, using acceleration data loggers. Deep-Sea Res II 88-89: $14-22$

Gentry RL, Kooyman GL (1986) Fur seals: maternal strategies on land and at sea. Princeton University Press, Princeton, NJ

> Guinet C, Vacquié-Garcia J, Picard B, Bessigneul G and others (2014) Southern elephant seal foraging success in relation to temperature and light conditions: insight into prey distribution. Mar Ecol Prog Ser 499:285-301

> Hanuise N, Bost CA, Huin W, Aubert A, Halsey LG, Handrich Y (2010) Measuring feeding activity in a deep diving bird: comparing wiggles, oesophageal temperatures and beak-opening angles as proxies of feeding. J Exp Biol 213:3874-3880

> Hindell MA, Slip DJ, Burton HR (1991) The diving behaviour of adult male and female southern elephant seals, Mirounga leonina (Pinnipedia: Phocidae). Aust J Zool 39: 595-619

Houston AI, Carbone C (1992) The optimal allocation of time during the diving cycle. Behav Ecol 3:255-265

Hulley PA (1990) Family Myctophidae In: Gon O, Heemstra PC (eds) Fishes of the Southern Ocean. JLB Smith Institute of Ichthyology, Grahamstown, p 146-178

> Jonsen ID, Myers RA, James MC (2007) Identifying leatherback turtle foraging behavior from satellite telemetry using a switching state-space model. Mar Ecol Prog Ser 337:255-264

Kareiva P, Odell G (1987) Swarms of predators exhibit 'preytaxis' if individual predators use area-restricted search. Am Nat 130:233-270

Knoppien P, Reddingius J (1985) Predators with two modes of searching: a mathematical model. J Theor Biol 114: 273-301

McConnell BJ, Chambers C, Fedak MA (1992) Foraging ecology of southern elephant seals in relation to the bathymetry and productivity of the Southern Ocean. Antarct Sci 4:393-398

McIntyre T, de Bruyn PJN, Ansorge IJ, Bester MN, Bornemann H, Plötz J, Tosh CA (2010) A lifetime at depth: vertical distribution of southern elephant seals in the water column. Polar Biol 33:1037-1048

McIntyre T, Bornemann H, de Bruyn PJN, Reisinger RR and others (2014) Environmental influences on the at-sea behaviour of a major consumer, Mirounga leonina, in a rapidly changing environment. Polar Res 33:23808

McMahon CR, Burton HR, McLean S, Slip DJ, Bester MN (2000) Field immobilisation of southern elephant seals with intravenous tiletamine and zolazepam. Vet Rec 146: 251-254

> Morales JM, Haydon DT, Frair J, Holsinger KE, Fryxell JM (2004) Extracting more out of relocation data: building movement models as mixtures of random walks. Ecology 85:2436-2445

- Mori Y (1998) The optimal patch use in divers: optimal time budget and the number of dive cycles during bout. J Theor Biol 190:187-199

Morris DW, Kotler BP, Brown JS, Sundararaj V, Ale SB (2009) Behavioral indicators for conserving mammal diversity. In: Ostfeld RS, Schlesinger WH (eds) Year in ecology and conservation biology 2009, Book 1162. Blackwell Publishing, Oxford

> Naito Y, Costa DP, Adachi T, Robinson PW, Fowler M, Takahashi A (2013) Unravelling the mysteries of a mesopelagic diet: a large apex predator specializes on small prey. Funct Ecol 27:710-717

R Development Core Team (2010) R: a language and environment for statistical computing. R Foundation for Statistical Computing, Vienna. www.r-project.org. Accessed June 2010

> Rodhouse P, Arnbom T, Fedak M, Yeatman J, Murray A (1992) Cephalopod prey of the southern elephant seal, Mirounga leonina. Can J Zool 70:1007-1015

Slip DJ (1995) The diet of southern elephant seals Mirounga leonina from Heard Island. Can J Zool 73: 1519-1528

Suzuki I, Naito Y, Folkow LP, Miyazaki N, Blix AS (2009) Validation of a device for accurate timing of feeding events in marine animals. Polar Biol 32:667-671

Thompson D, Hiby AR, Fedak MA (1993) How fast should I swim? Behavioural implications of diving physiology. Symp Zool Soc Lond 66:349-368

Thums M, Bradshaw CJA, Hindell MA (2008) A validated approach for supervised dive classification in diving vertebrates. J Exp Mar Biol Ecol 363:75-83

> Thums M, Bradshaw CJA, Hindell MA (2011) In situ measures of foraging success and prey encounter reveal marine habitat-dependent search strategies. Ecology 92: 1258-1270

Vacquié-Garcia J, Royer F, Dragon A-C, Viviant M, Bailleul F, Guinet C (2012) Foraging in the darkness of the South- 
ern Ocean: influence of bioluminescence on a deep diving predator. PLoS ONE 7:e43565

- Viviant M, Trites AW, Rosen DAS, Monestiez P, Guinet C (2010) Prey capture attempts can be detected in Steller sea lions and other marine predators using accelerometers. Polar Biol 33:713-719

Viviant M, Monestiez P, Guinet C (2014) Can we predict foraging success in a marine predator from dive patterns only? Validation with prey capture attempt data. PLoS ONE 9:e88503

Weimerskirch H, Pinaud D, Pawlowski F, Bost CA (2007) Does prey capture induce area-restricted search? A finescale study using GPS in a marine predator, the wandering albatross. Am Nat 170:734-743

Editorial responsibility: Scott Shaffer, San Jose, California, USA
Williams A, Koslow JA (1997) Species composition, biomass and vertical distribution of micronekton over the midslope region off southern Tasmania, Australia. Mar Biol 130:259-276

Wilson RP, Cooper J, Plotz J (1992) Can we determine when marine endotherms feed? A case study with seabirds. J Exp Biol 167:267-275

Wilson R, Steinfurth A, Ropert-Coudert Y, Kato A, Kurita M (2002) Lip-reading in remote subjects: an attempt to quantify and separate ingestion, breathing and vocalisation in freeliving animals using penguins as a model. Mar Biol 140:17-27

Zuur AF, Ieno EN, Smith GM (2007) Analysing ecological data. Springer, New York, NY

Submitted: February 10, 2015; Accepted: October 6, 2015 Proofs received from author(s): December 7, 2015 